\title{
El Enanismo en la Cerámica del Perú Precolombino
}

\author{
Dwarfism in Pre-Columbian Peru Pottery
}

Emiliano Paico Vílchez ${ }^{1}$

\begin{abstract}
RESUMEN
Además de evocar la preciosa historia de las antiguas culturas peruanas, que exige salvaguardar la memoria social y el patrimonio cultural de ellas, se hace una somera revisión de la existencia del enanismo entre los aborígenes del Perú precolombino.

La cerámica precolombina es fiel testimonio de la existencia de esa rara malformación. En sus preciosos ceramios están representados espléndidamente varones adultos con las típicas características de enanismo acondroplásico.
\end{abstract}

Palabras claves: Enanismo, acondroplasia, cerámica, precolombino, Perú.

\section{Abstract}

In addition to evoking the valuable history of the ancient Peruvian cultures, which requires safeguarding the social memory and the cultural heritage of them, a brief review of the existence of Dwarfism among the aborigines of preColumbian Peru is made.

Pre-Columbian pottery is a faithful testimony to the existence of this rare malformation. In their precious potteries, splendidly adult males are represented with the typical features of achondroplastic dwarfism.

Key words: dwarfism, achondroplasia, pottery, preColumbian, Peru.

\begin{abstract}
(1) enanismo, rara malformación Scongénita, se ha conocido desde tiempos muy remotos en las diferentes antiguas culturas del mundo. Los aborígenes del antiguo Perú también la adolecieron. Las crónicas y la cerámica del Perú precolombino nos proveen evidencias de la existencia de esa malformación.
\end{abstract}

Los alfareros del Perú precolombino, no sólo elaboraron esplendidos ceramios desde el punto de vista artístico sino que en ellos plasmaron espléndidamente escenas y personajes con admirable veracidad, constituyendo valiosos testimonios de naturaleza arqueológica para las diversas ramas del saber humano. La cerámica, con el elevado grado de perfección que alcanzó, especialmente la cultura Mochica, constituye una de las fuentes arqueológicas de importante valor para reconstruir la medicina aborigen peruana. ${ }^{(1)}$

Aunque la etiología de la acondroplasia

1 Cirujano pediátrico del Hospital Belén de Trujillo. Profesor de la Universidad Privada Antenor Orrego, Trujillo. 
fue reportada recién en 1994, la evidencia de la existencia de esta enfermedad ha sido encontrada en las poblaciones del antiguo Egipto (2500 a C) y ha sido documentada en las poblaciones americanas antiguas (entre el 300 a C. y el 1500 a C.). ${ }^{(2-3)}$

Actualmente se sabe que las causas del enanismo pueden ser de origen hormonal, nutricional, por cuadros sindrómicos de muy baja talla con displasias no óseas, de talla baja moderada acompañada de anomalías faciales o genitales, trastornos de depósito, baja talla por defectos de las extremidades o por algún tipo de osteocondrodisplasia como manifestaciones principales. ${ }^{(4)}$

El tipo de enanismo más frecuente es el acondroplásico; $y$, su incidencia es de un caso por cada 15,000 a 20,000 recién nacidos vivos. Los individuos presentan acortamiento rizomélico de las extremidades, facies característica con prominencia frontal, hipoplasia de la mitad de la cara, genu varo y mano tridente. La acondroplasia es un trastorno autosómico dominante; la mayoría de los casos son esporádicos, resultado de una mutación de novo, una mutación en el gen del receptor 3 del factor de crecimiento de fibroblastos, FGFR3. ${ }^{(5)}$

Virginia Miller analizó las fuentes iconográficas en un contexto histórico real y en un contexto sobrenatural y manifestó que si bien la mayoría de las representaciones en los restos arqueológicos de enanos y otras curiosidades o rarezas humanas pueden ser ubicadas en un contexto histórico, muchas de ellas tienen lugar en un entorno sobrenatural. ${ }^{(6)}$

El enanismo sería un fenómeno poco común, según las fuentes arqueológicas. Sin embargo, la documentación escrita y la cerámica los muestra como parte del mundo sobrenatural, relacionados con diferentes aspectos del mundo subterráneo y de la regeneración de las divinidades y la personificación de los númenes, de allí el hecho de que su compañía sea tan deseada por los gobernantes. ${ }^{(6)}$

Por otra parte, Prager referido por María Luisa Garde, manifiesta que ningún enano de la cultura maya "fue miembro de la casa gobernante, porque de lo contrario habría recibido dicho nombre propio", ni perteneció a la élite. Los enanos no sólo están presentes en la corte, sino que además hacen todo lo necesario para garantizar el bienestar del gobernante $\mathrm{y}$ su familia; examinan la calidad de los regalos, participan en el aseo corporal del mandatario y sirven las comidas o entretienen a este y a sus invitados en danzas y presentaciones musicales. Prager, indicaría que estos individuos "no estuvieron marginados en la sociedad prehispánica sino que gracias a sus atributos divinos fueron miembros apreciados de la corte". ${ }^{(7)}$

Rodríguez y colaboradores ${ }^{(8)}$ refirieron que los estudios de los últimos treinta años dentro de los campos de la arqueología e iconografía han demostradoquelosindividuosacondroplásicos fueron considerados seres especiales en las sociedades precolombinas de Mesoamérica y América del Sur, donde cumplieron un gran número de funciones en la vida cotidiana, así como en diferentes ritos asociados con las divinidades. Entre los antiguos mayas, trabajaron en la administración del Estado y los encontramos en el ámbito de la cultura como artistas, generalmente músicos. Las personas de talla pequeña podían servir a los gobernadores y eran sus acompañantes en diversos actos públicos y religiosos. También se encuentran representadas en escenas de canto y baile asociadas a actividades chamánicas o a los ritos en los que participaban los gobernadores y los dioses. Por su condición de 
seres diferentes, se creía, como ya se mencionó anteriormente, que ellos tenían poderes sobrenaturales y servían de conexión con el mundo de los muertos. Para estas culturas el poder estaba representado como algo que reside abajo, de ahí que las personas de baja estatura fuesen respetadas.

En el antiguo Perú, a los recién nacidos con alguna malformación congénita externa la sociedad los protegía, pues la malformación congénita era un signo de poseer poderes sobrenaturales. En relación al reconocimiento de casos de enanismo por parte de los aborígenes peruanos, se cree que en la etapa neonatal era difícil diferenciarlos de los neonatos normales por lo que tenía que pasar algunos meses hasta que las características físicas fuesen más evidentes. A partir de ese momento se les consideraban como seres dotados de características y poderes especiales. La anterior consideración explicaría el porqué de la frecuente representación de enanos en el arte prehispánico americano.

Guamán Poma de Ayala, cronista peruano, nos cuenta que en Cusco los emperadores incas reunían en un mismo barrio a enanos, ciegos, jorobados, mudos y a los que tenían la nariz hendida (labio leporino), cojos, etc., obligándoles a casarse entre los que tenían el mismo defecto o malformación con el objetivo que no se extinguiesen; además, estaban al servicio del inca. ${ }^{(9)}$

Juan de Betanzos, cronista español de la conquista, relata la práctica de usar a personas con enanismo como chivos expiatorios y cuenta las peripecias de uno llamado Chimbo Sancto, capturado por Huayna Cápac, uno de los últimos gobernantes incas. ${ }^{(10)}$

A continuación presentaremos algunos ceramios de la cultura Mochica que representan individuos con las típicas características de enanismo acondroplásico (Figuras 1a y 1 b). Algo que llama la atención en el estudio de estos ceramios, es el hecho que en las representaciones aparecen sólo varones $\mathrm{y}$ no mujeres, no obstante que sabemos hoy en día que esta malformación afecta por igual a ambos sexos. La explicación tal vez sería que en las sociedades precolombinas les dieron a los varones una valoración superior que a las

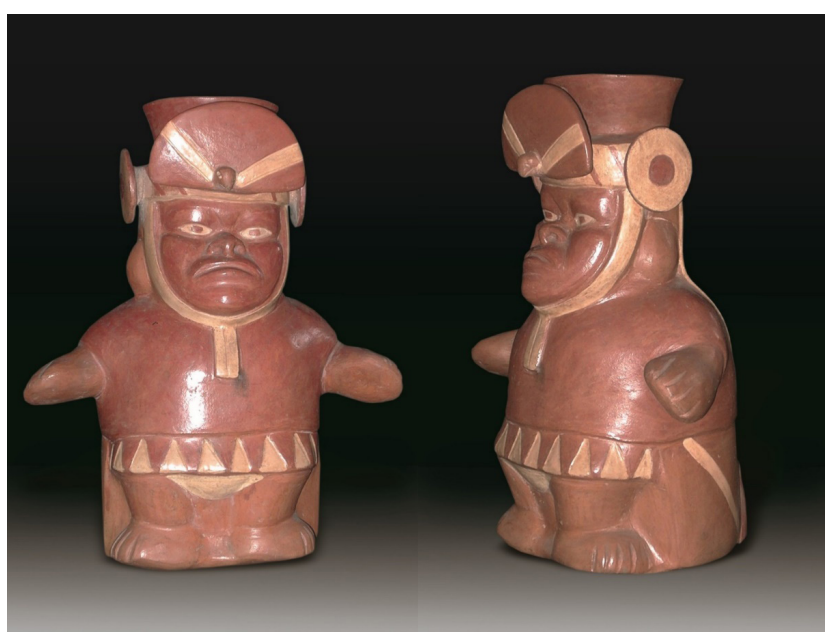

Figuras 1a y 1b. Adulto con enanismo acondroplásico. Cerámica Mochica. Museo Arqueológico Casinelli, Trujillo.

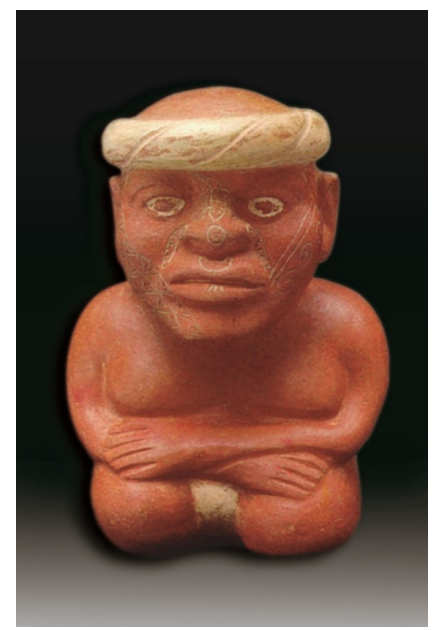

Varón adulto arrodillado, con la cara tatuada y con las características típicas de enanismo acondroplásico. Cerámica mochica. Museo Nacional de Arqueología, Antropología e Historia del Perú, Lima. 


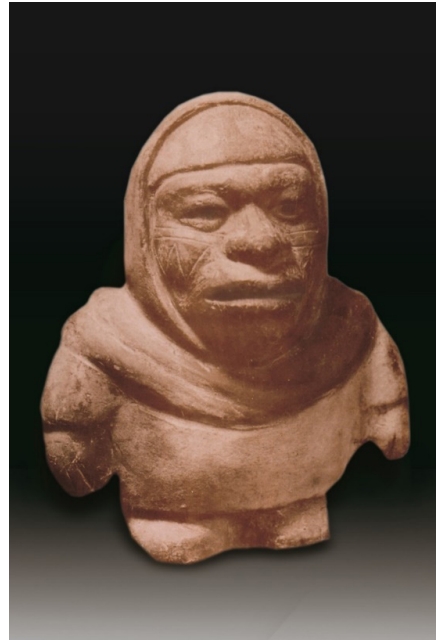

Figura 3. Varón adulto con enanismo acondroplásico y con la cara tatuada. Cerámica mochica. MNAAHP, Lima.

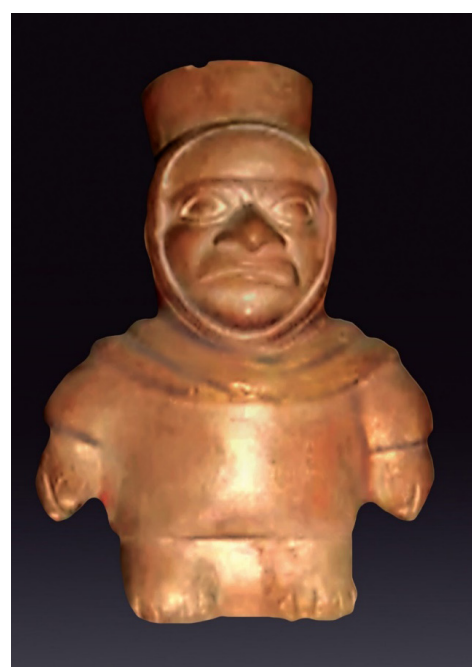

Figura 4. Varón adulto con enanismo acondroplásico. Cerámica mochica. MNAAHP, Lima. mujeres.

\section{ReFERENCIAs BibliográficAs}

1. Lastres, Juan B. Representaciones patológicas en la cerámica peruana. Imprenta del Museo Nacional, $\mathrm{N}^{\circ} 4$, Lima, 1943.

2. Sotomayor Tribín, Hugo. Enanos y gigantes en mitologías indígenas y la arqueología en Colombia. Repert Med Cir. 2007; 16 (2): 96-104.

3. Sotomayor Tribín, Hugo. Enanismo. Representaciones Artísticas en América Prehispánica y otras Sociedades. Repert Med Cir. 2014; 23(4): 299-313.

4. Jones KL.Smith Patrones reconocibles de malformaciones humanas. 6a ed. Madrid: Elsevier / Saunders; 2007.

5. Velinov M, Slaugenhaupt SA, Stoilov I, Scott CI Jr, Gusella Jf, Tsipouras P. El gen para la acondroplasia se asigna a la región telomérica del cromosoma 4p. Nat Genet. 1994; 6 (3): 314-317.

6. Miller, Virginia. The dwarf motif in classic Maya art. En: Greene R.M. y Benson, E.P. (eds.), Fourth Palenque Round Table. San Francisco, Pre-Columbian Art Research Institute. 1980, VI, pp: 141-153.

7. Garde Etayo, María Luisa. La acondroplasia en la historia. Una aproximación historiográfica. URL disponible en: www.fundacionalpe.org/images/ alpe / library / societyEN / La-acond roplasia-en-lahistoria-Garde-E.pdf

8. Rodríguez C, Isaza C. y Pachajoa H. Achondroplasia among ancient populations of mesoamerica and South America: Iconographic and Archaeological Evidence. Colombia Médica. 2012; 43 /3.

9. Guamán Poma de Ayala, F.: Nueva Crónica y Buen Gobierno. México. Tomo I, Lima, Ed. Fondo de Cultura Económica, 2005/ 1615.

10. Betanzos, Juan Diez de: Suma y Narración de los Incas. Madrid Atlas, 1987/ 1551.

\section{CORRESPONDENCIA:}

epaicov@gmail.com 